\title{
Bush II, Davos y Porto Alegre 2005
}

\author{
F. Javier Ibisate ${ }^{*}$ S. J. \\ Universidad Centroamericana "José Simeón Cañas" \\ El Salvador
}

\section{Resumen}

En este artículo, el autor no solo expone la actuación reciente de las principales potencias mundiales y su repercusión a nivel mundial, en todos lo ámbitos, sino que también analiza de manera paralela los movimientos que tiene cada uno de estos protagonistas y la relación que se establece, en consecuencia, a raíz de sus diferentes acciones. Su análisis acompaña los distintos acontecimientos para poner de manifiesto la intencionalidad de sus actores.

\section{Un tiempo de catástrofes}

Este año se dejaron de vender millares de tarjetas con las que tradicionalmente deseamos un "feliz año nuevo" a nuestras amistades. En las dos primeras semanas de enero se vivió lo que el diario Le Monde tituló "Un tiempo de catástrofes". "La mundialización de las imágenes del tsunami sudasiático, angustia compartida a distancia, drama comunitario, presencia obsesiva de cuerpos sin sepultura, multitud de interrogantes sobre la imprevisión (¿era evitable?, ¿se pudo evitar a tiempo?); interrogantes sobre las prioridades de un mundo que, lejos de estar protegido por la acumulación de riquezas y la carrera del crecimiento, parece en- caminarse a su perdición. En este sentido, hay un eco y una resonancia entre el desastre de la naturaleza y el otro, el desastre de la guerra" (Le Monde, 8 de enero de 2005).

En la encuesta hecha por la $B B C$, en veintiún países, el 58 por ciento afirma que la reelección de George W. Bush ha convertido el mundo en un lugar más peligroso. "Esto es un retrato bastante sombrío de Estados Unidos en el mundo", asegura Steven Kull, uno de los directores del programa. Al mismo tiempo, el mundo espera cambios de Estados Unidos. Europa espera un cambio radical en las visitas de Bush a la OTAN y a la Unión Europea, en Bruselas, en lo que respecta a las rela-

* Catedrático del Departamento de Economía de la UCA. 
ciones transatlánticas. Entonces, algunos autores le recordarán a Bush que está visitando el Estados Unidos de Europa, primera potencia económica mundial. Por ello, habrá que tratar en forma más dialogada el problema del Medio Oriente, al cual se unen, repentinamente, dos problemas, el programa de energía nuclear en Irán ("Divergencias americanas-europeas sobre Irán", Le Monde, 9 de febrero de 2005) y la abierta confesión del gobierno norcoreano ("Corea del Norte afirma estar dotado de la bomba atómica", Le Monde, 10 de febrero de 2005).

El mundo árabe espera que Estados Unidos sea un mediador imparcial, y el gobierno israelí espera que siga siendo "su mejor amigo". América Latina espera que Bush le preste un poco más de atención, aunque difieran sus intereses; los gobiemos de Argentina, Brasil o Venezuela maniobran hacia la izquierda y los de Colombia y Centroamérica, hacia la derecha. El grueso de las naciones latinoamericanas coincide en reclamar mayores facilidades comerciales y migratorias. África espera el alivio de la pobreza y de la deuda externa, y un mayor avance en el proceso de liberalización del comercio mundial ("Lo que el mundo espera de los Estados Unidos", El País, 21 de enero de 2005).

A finales de enero, tres visiones, dos de ellas en plena oposición, iluminan la problemática mundial del año 2005. La primera visión se afianza en el discurso del presidente Bush del 20 de enero. Este sustituyó el concepto de terrorismo por el de "tiranía", de manera que "al eje del mal" (Irán, Corea del Norte y el ahora democrático Irak de las elecciones) sea agregado, en la agenda de Condoleeza Rice, "el eje de la tiranía" - Cuba, Birmania, Bielorrusia, Zimbabwe...-. Se anuncian serias amonestaciones a V. Putin, por sus nuevas políticas antidemocráticas de control ciudadano (por cierto, similares a las aplicadas en Estados Unidos, después del 11 de septiembre), al mismo tiempo que la Secretaria de Estado se muestra "profundamente preocupada por la estrecha asociación entre Hugo Chávez y Fidel Castro", así como por su oposición al Área de Libre Comercio de las Américas (ALCA) y la creación de una alternativa, el Área Bolivariana ("Condoleeza Rice diseña su proyecto de política extranjera", Le Monde, 18 de enero de 2005; "Condoleeza Rice asegura que para EE.UU ha llegado la hora de la diplomacia", El País, 19 de enero de 2005). Esta visión presagia "la diplomacia de las cañoneras".

Más cercano a la problemática mundial es -en sus enunciados - el programa presentado en el foro económico mundial de Davos 2005. Los 2500 asistentes escogieron seis temas principales para reflexionar: la lucha contra la pobreza (64 por ciento), una globalización equitativa (55 por ciento) y los cambios climáticos (51 por ciento). Le siguen en importancia la educación, el conflicto del Próximo Oriente y "el buen gobiemo" en el tercer mundo. Por razones diplomáticas y para atraer a los miembros del gobierno de Bush hacia estos objetivos humanitarios, algunos jefes de Estado europeos forzarán una ensayada sonrisa cuando reciban al presidente estadounidense y a su Secretaria de Estado, y evitarán toda mención explícita al "agujero negro de Irak". Después de todo, el terrorismo también es una amenaza que se cierne sobre las capitales europeas - aunque no sobre todas - y poco es lo que se puede hacer en el mundo económico sin la colaboración de Estados Unidos. El objetivo son las buenas relaciones transatlánticas. Triste sería que por salvaguardar esas relaciones norte-norte, se olvidaran y sacrificaran las promesas hechas en Davos 2005.

El programa más universal se desglosó en el quinto foro social mundial de Porto Alegre, que congregó a unos 150 mil inconformes con la globalización actual. En 200 talleres, distribuidos en la última semana de enero, enfatizan que "otra globalización es posible", aquella que abre el espacio a toda la humanidad. Porto Alegre ha reventado, porque no caben todos; porque todos quieren oír a todos en las lenguas de 175 países, sobre problemas diferentes. Porto Alegre se irá celebrando en diversas fechas y localidades del mundo cuando se congreguen el G-8, el Fondo Monetario Internacional, el Banco Mundial y la Organización Mundial del Comercio. Como Porto Alegre no es una reunión de diplomáticos, las marchas pacíficas combinan las demandas de la reducción de la deuda externa de los países más pobres con la condena de la guerra de Irak y las amenazas de invasión a Irán y a otros "ejes de la tiranía". El 19 de marzo, en muchas ciudades del mundo se congregarán millones de inconformes para recordar que en ese día del año 2003 "las tropas de la coalición iniciaron la guerra de la mentira".

Con peligro de una equivocación involuntaria, en este año 2005, hay mayor cercanía entre las preocupaciones del foro social de Porto Alegre y del foro económico de Davos. En consecuencia, se observa un distanciamiento mayor entre el fundamentalismo mesiánico de Bush, y su sombra Condoleeza Rice, sin mencionar el criticado Rumsfeld, y la visión más humanista de la "vieja Europa" y 
el bloque del tercer mundo. Se ha dicho que 2005 es la "última alternativa" para responder a los problemas económicos. La guerra contra la extrema pobreza, de la cual se habló en Davos y Porto Alegre, significa defender la consigna de la guerra "contra la guerra", que otros anuncian. En su momento, la historia nos dirá por dónde caminará el año 2005.

\section{2. "No hay armas de destrucción masiva en Irak"}

El gobiemo de Estados Unidos reconoció públicamente el falso testimonio dado por Collin Powell, el 5 de febrero 2003, ante el Consejo de Seguridad de Naciones Unidas - Le Monde lo tradujo verbatim, el 16 de noviembre de 2004-. Mintió Powell, mintió el informe de la CIA y Bush repite las mismas mentiras, en sus discursos a la nación del 6 y 16 de marzo de 2003. Dadas las consecuencias humanas y morales de esta mentira, el gobierno de Bush ha perdido toda credibilidad moral.

Propiamente, no reconoce la mentira, sino que se dice de manera sutil: "EE.UU desiste de la búsqueda de armas de destrucción masiva en Irak" ( $E l$ País, 13 de enero de 2005) o "Los norteamericanos abandonan la búsqueda de armas de destrucción masiva de Saddam Hussein" (Le Monde, 13. de enero de 2005). La búsqueda de armas se cerró sin la más mínima prueba de su existencia. El informe final del jefe de inspectores, Charles Duelfer, no deja espacio a la duda. "El portavoz de la Casa Blanca confirmó el fin de las operaciones de búsqueda de armas de destrucción masiva en Irak, cuya supuesta existencia permitió a Bush y a sus aliados la justificación de la guerra. Según este informe, Saddam Hussein no solo no tenía armas de destrucción masiva desde 1991, sino que carecía de capacidad para fabricarlas y de la intención de encargarlas". Se trata de un equipo de 1200 efectivos, que están convencidos de haber interrogado a todas las personas que pudieran haber estado implicadas en los programas de fabricación de dichas armas de destrucción masiva. Incluso los responsables del equipo pidieron al Pentágono liberar a varios detenidos por su excelente grado de colaboración y su nula implicación en la supuesta fabricación de armas, pero el Departamento de Defensa se resiste a dejarlos en libertad (El País, 13 de enero de 2005).

El corresponsal de Le Monde agrega algunos datos nuevos. En la cadena de televisión $A B C$, Bush declaró que no lamenta en nada haber invadido Irak. "Yo pensaba que íbamos a encontrar ar-

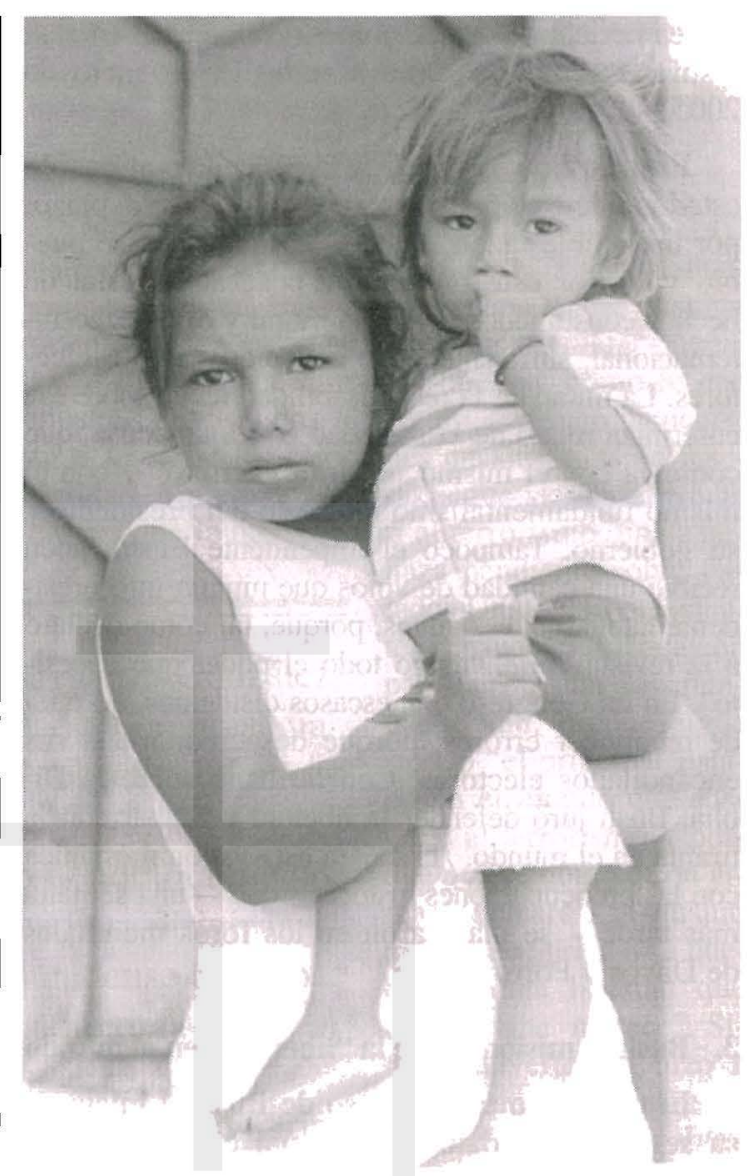

mas de destrucción masiva. Muchas personas en Estados Unidos, muchas personas en el mundo, en Naciones Unidas, pensaban que Saddam Hussein tenía armas de destrucción masiva, y nosotros debemos hallar qué es lo que ha fallado en el levantamiento de los datos. Saddam era peligroso, y el mundo es un lugar más seguro ahora que él no goza de poder". El informe de Charles Duelfer confirma las conclusiones del informe de octubre de 2003 del anterior jefe de inspectores David Kay. Lo doblemente inmoral es que el informe Duelfer ha sido presentado al Senado en febrero de 2005 , "porque no convenía reconocer públicamente, antes de las elecciones del 2 de noviembre, que la principal justificación de la guerra era falsa". Nancy Pelosy, jefa de la fracción demócrata de la Cámara de representantes, pidió una rendición de cuentas. "El presidente Bush se ha negado a reconocer lo que era evidente desde hace meses: la justificación mayor para invadir Irak no encaja con los hechos. Ahora el presidente Bush debe explicar al pueblo 
norteamericano por qué cometió semejante error al justificar la guerra" (Le Monde, 13 de enero de 2005).

Esta explicación no le será concedida al pueblo estadounidense, por lo menos en el corto plazo, por una doble razón. Más de la mitad de ese pueblo votó por este presidente, pese al historial de hechos consumados contra la moral y el derecho internacional, suficientemente conocidos por los electores. La mitad de la responsabilidad recae sobre esa enfermiza mitad de la sociedad estadounidense, que comulga con el mismo "espíritu guerrero" y con el mismo fundamentalismo religioso del presidente y su gobierno. Tampoco el impenitente Bush, quien recibió una cantidad de votos que ningún otro presidente había recibido antes, porque, tal como declaró a la revista Time, "tengo todo el poder que necesito". En un Congreso con escasos disidentes, no puede reconocer errores, porque desacreditaría a sus encandilados electores. Con la mano sobre la $\mathrm{Bi}$ blia, Bush juró defender la libertad y acabar con la tiranía en el mundo. ¿Encajará esta visión mesiánica con las preocupaciones históricas que - una semana más tarde - se plantearon en los foros mundiales de Davos y Porto Alegre?

\section{Bush II misionero de la "libertad" en el mundo}

El contenido del discurso de Bush al inicio de su segundo mandato presidencial era de esperar, pero ciertos matices cambiaron. El nombramiento de Alberto González como Ministro de Justicia no presagia grandes avances en el respeto al derecho internacional de los prisioneros de guerra. Según Human Rights, este consejero de Bush traducía a su guisa (military order) los acuerdos de la convención de Ginebra ("George Bush nombra a una persona de confianza para el Ministerio de Justicia", Le Monde, 11 de noviembre de 2004). Tampoco el nombramiento de Condoleeza Rice para dirigir la diplomación estadounidense ha sido bien visto por los diplomáticos europeos, porque puede hacer más difíciles las relaciones con Washington. El contexto en el cual la nueva ministra de relaciones exteriores desarrollará sus obligaciones ha sido establecido por el propio presidente Bush: "Una vez confirmada por el Senado, Condoleeza Rice iniciará sus funciones en un momento crítico para nuestro país. Somos una nación en guerra. Dirigimos una importante coalición contra un enemigo determinado. Aplicamos nuevas técnicas e instituciones para enfrentar a regímenes fuera de la ley, para oponer- nos a la proliferación de armas y de productos peligrosos y para quebrar las redes terroristas. Estados Unidos ha respondido al llamado de la historia para ayudar a las fuerzas de la reforma y de la libertad en el gran Medio Oriente, para que esta región pueda desarrollarse por la vía de la esperanza y no de la cólera" ("El nombramiento de Condoleeza Rice confirma el conservadurismo del gobierno de Bush", Le Monde, 16 de noviembre de 2004).

Algunos corresponsales señalan que, en el discurso de Bush del 20 de enero de 2005, la palabra freedom-liberty aparece 42 veces, "tiranía", cinco veces, y "democracia", una vez. No aparecen, en cambio, los términos Irak, terrorismo y armas de destrucción masiva. No convenía utilizar palabras "escurridizas", en un discurso de toma de posesión. Uno de los ejes del mensaje fue que "La supervivencia de la libertad en Estados Unidos depende del éxito de la libertad en el mundo entero. La mayor esperanza de paz, en nuestra nación, es el desarrollo de la libertad en el mundo entero. La política de Estados Unidos es apoyar y sostener los movimientos y las instituciones democráticas, en todos los países y en todas las sociedades para poner fin a la tiranía en el mundo. Esto no se logra propiamente con las armas, pero nos defenderemos, a nosotros y a nuestros amigos, con la fuerza de las armas, si es necesario. Aquellos que viven en la tiranía y en la desesperanza deben saber que Estados Unidos no ignora su opresión, ni protege a sus opresores. Cuando defiendan su libertad, estaremos con ellos. Mi principal deber es proteger a esta nación y a su pueblo contra nuevos ataques y posibles amenazas. Algunos, imprudentemente, han escogido poner a prueba nuestra determinación y han visto que era muy firme. El poder de Norteamérica no es ilimitado pero, para dicha de los oprimidos, es considerable y lo utilizaremos con confianza para defender la libertad. No hay justicia sin libertad, no hay derechos humanos sin libertad" ("George W. Bush presta juramento", Le Monde, 20 de enero de 2005; "Bush: la supervivencia de la libertad en EEUU depende del éxito de la libertad en otros países", El País, 20 de enero de 2005; "Bush II, misionero de la libertad en el mundo", Le Figaro, 22 de enero de 2005).

Los principales diarios revelaron que, al día siguiente, recibieron un aviso de La Casa Blanca, enviado de forma anónima, en el cual se indicaba que el discurso presidencial no debía ser tomado 
al pie de la letra, sino como un reflejo de las convicciones íntimas del propio presidente. No se trata de un plan de acción que obligue a acabar con la tiranía. Aunque el discurso conlleva "implicaciones políticas", "no quiere decir que esto es lo que ya queremos hacer". No se trata de generar temores en países como China, Rusia, Pakistán y Egipto. Sin embargo, el antiguo consejero de Jimmy Carter, Z. Brzezinsky, adoptó una posición crítica. "Si hubiera que tomar el discurso al pie de la letra, significaría una cruzada norteamericana a través del mundo entero. En la práctica no veo cómo se podría llevar a cabo" y menciona los casos de China, Rusia, Tibet y Chechenia. Si no es un programa de acción, entonces, el presi-

dente Bush ha reformateado su discurso. "En vez de hablar de miedo, habla de libertad. En vez de hablar de terrorismo, habla de tiranía". Otros lo han tomado más en serio: "El presidente ha dicho que la libertad de Norteamérica no está segura mientras no lo esté en el resto del mundo. Esta es una afirmación demasiado audaz. Sus implicaciones son considerables". Algunos republicanos tradicionales se sitúan entre los más críticos. "Bush ha afirmado el derecho a intervenir en los asuntos internos de cualquier país. Esta es la consigna para una guerra sin fin y la guerra es la muerte de las repúblicas", dijo Pat Buchanan, antiguo consejero de Reagan ("La Casa Blanca minimiza el alcance del discurso de la libertad de Bush", Le Monde, 22 de enero de 2005).

El futuro próximo desvelará la traducción real de este discurso. Rice ha prometido "servir a su gran país y a la causa de la democracia que representa, y dedicarse a favorecer la libertad en el mundo. Trabajaremos en colaboración con nuestros aliados y reformistas en el mundo, utilizando las herramientas de la diplomacia para unir, fortalecer y ampliar la comunidad de las democracias. En el Departamento de Estado, aplicaremos una política exterior que vea al mundo como es. Pero no aceptaremos que la realidad que hoy es, tenga que ser también la de mañana". Bush agregó que Rice tiene "una firme creencia en el poder de la democracia para garantizar la justicia y la libertad" ("Condoleeza Rice dice que luchará por la democratización del mundo", El Mundo, 20 de enero de 2005).

\section{De Irak a Irán "y tiro porque me toca"}

En su discurso sobre el estado de la nación del 3 de febrero de 2005, Bush habló de "la nueva situación política en Irak, que abre una nueva fase de nuestra misión en este país. Vamos a triunfar porque los iraquíes aman su propia libertad, como lo han mostrado ante todos el pasado domingo", cuando se celebraron las elecciones en situación de inseguridad. Sin embargo, "Irak sigue siendo el frente central" de la lucha contra el terrorismo, una amenaza pendiente sobre Estados Unidos. El presidente aprovechó la ocasión para lanzar una advertencia a Irán, porque sigue siendo "el principal Estado en el mundo que sostiene al terrorismo y porque quiere dotarse con armas nucleares, al mismo tiempo que priva a su pueblo de una libertad que busca y que merece". Similar advertencia hizo a Siria para que cesara su apoyo al terrorismo y abriera sus puertas a la libertad. Acusó al gobierno de Damasco "de seguir permitiendo que su territorio y algunas zonas de El Líbano sean utilizados por terroristas, empeñados en impedir toda oportunidad de paz en la región". También pidió a los gobiernos amigos de Arabia Saudita y Egipto llevar adelante las reformas democráticas, en la línea de los esfuerzos estadounidenses "para promover la paz y la estabilidad en el gran Medio Oriente". Hizo una breve referencia a Corea del Norte e indicó que Estados Unidos "trabaja en estrecha colaboración con los gobiernos de Asia para convencer a Corea del Norte a que abandone sus ambiciones nucleares" ("Bush optimista sobre Irak y la democratización del Próximo Oriente", Le Monde, 3 de febrero de 2005). Con estas advertencias, Bush comenzó a traducir aquella frase de su discurso del 20 de enero, "La supervivencia de la libertad en Estados Unidos depende del éxito de la libertad en otros países".

Dos días más tarde, Rice, de visita en Berlín, expresó su preocupación por las intenciones del 
gobierno de Irán. "Los iraníes no han demostrado hasta el presente estar dispuestos a observar sus obligaciones internacionales. Esto es preocupante, no solo para Estados Unidos, porque esta inquietud la ha planteado la Agencia Internacional de la Energía Atómica (AIEA) y en otros coloquios mundiales". Sin embargo, la Secretaria de Estado añadió que "no era parte de la agenda del día un ataque a Irán". Aunque un ataque a Irán no sea parte de la agenda de febrero, esta simple afirmación nos recuerda la resolución 1441 , del 8 de noviembre de 2002, que "conmina al gobierno de Irak por no cumplir con las condiciones de desarme". El canciller alemán Schröder observó que si Irán tienen derecho a utilizar la energía nuclear para fines civiles, no debe fabricar armas nucleares. Por eso, los gobiemos europeos buscan "una solución diplomática y política" "'En visita a Berlín, Condoleeza Rice mantiene sus críticas a Irán", Le Monde, 5 de febrero de 2005).

En los meses de enero y febrero de 2003, Hans Blix, jefe de los inspectores de Naciones Unidas, solicitó más tiempo para llevar a cabo su tarea, porque las armas de destrucción masiva no aparecían y el gobierno de Irak daba muestras de colaboración con Naciones Unidas. El 29 de enero de 2005, Mahomed el Baradei, director general del Organismo Intemacional de la Energía Atómica, dijo que "Irán está cooperando positivamente en las inspecciones nucleares, Hay negociaciones en curso entre la Unión Europea e Irán y se advierte un progreso importante. Tenemos que garantizar a aquellos países que lo necesitan el acceso al uranio enriquecido para fines pacíficos. $\mathrm{Y}$ al mismo tiempo debe aprobarse una moratoria general de cinco años para que nadie trate de enriquecer uranio". Mahomed el Baradei advirtió a Estados Unidos que "un ataque militar en territorio iraní solo empeorará las cosas".

Esta afirmación tiene su razón de ser. El senador republicano Saxby Chamblix explicó que "el gobierno de Bush contempla que Estados Unidos va a ser el objetivo de un próximo ataque terrorista y que probablemente se usará alguna arma de destrucción masiva. La capacidad nuclear de algunos estados podría pasar a manos de terroristas, como el grupo Al Qaeda, y esto nos parece relevante, porque esos grupos intentarían usarla". Esa es la lógica simplista del partido republicano para acusar a un país. Por ello, el Ministro de Asuntos Exteriores iraní, Kamal Jarrazi, explicó cuáles son las diferencias entre Irán y Corea del Norte. "Es una manipulación afirmar que ambos países tienen la mis- ma conducta. Irán es parte del Tratado de No Proliferación Nuclear. Corea del Norte se ha salido de él; Irán ha firmado el protocolo adicional que refuerza las inspecciones; Corea del Norte no lo ha rubricado; el Organismo Internacional de la Energía Atómica envía a sus inspectores; los inspectores no pueden entrar en Corea del Norte. Pero es que Corea del Norte reconoce su deseo de fabricar armas nucleares, e Irán afirma que no es su objetivo. Discrepo de lo que dice el senador. Si Irán tuviera energía nuclear, eso no supondría que ésta caería en manos de los terroristas. Usted está haciendo acusaciones sin pruebas. Es necesario recordar que $\mathrm{Al}$ Qaeda fue creada para hacer daño a Irán". El senador demócrata Edward Markey, luego de afirmar que "Estados Unidos no puede invadir Irán después de lo que ha caído en Irak", agrega, "aunque parece obvio que Estados Unidos no puede emprender una aventura, eso no quiere decir, desgraciadamente, que el gobierno de Bush desista de ello" ("El Baradei dice que un ataque de EE.UU a Irán empeoraría las cosas", El País, 30 de enero de 2005).

Si el vicepresidente Dick Cheney y la secretaria de Estado Rice agitan su miedo y su descontento por la conducta del gobierno de Irán, quiere decir que estamos hablando de una amenaza seria, que conlleva una crítica implícita a la trilogía de Inglaterra, Francia y Alemania, por no tomar más en serio la amenaza nuclear iraní. A mediados del mes de enero, el vicepresidente Cheney afirmó con claridad que Irán figura a la cabeza de las preocupaciones de Estados Unidos y agregó que Washington temía que los israelitas tomaran la iniciativa para destruir las instalaciones nucleares iraníes. El portavoz del Ministerio de Asuntos Exteriores iraní dijo que las amenazas de Cheney muestran que "el cabildeo sionista es poderoso en Estados Unidos" y que esta política "va a aislar más a Estados Unidos". Agregó que los organismos internacionales deben vigilar a Estados Unidos. "Las organizaciones intemacionales tienen el deber de frenar estas políticas y hacer que esos países se sometan a las normas internacionales". Estados Unidos, agregó el portavoz, se ha embarcado en una política "tiránica", que genera "una guerra cultural y religiosa" ("Irán advierte a Washington que no cometa un error estratégico", Le Monde, 23 de enero de 2005).

\section{Las primeras lecciones de Rice}

Apenas llegada a Bruselas, en preparación de la visita del presidente Bush, Rice recriminó de 
forma implícita al trío de Berlín, Londres y París, por no haber enfatizado con fuerza la amenaza de las sanciones de Naciones Unidas ante las repetidas tergiversaciones iraníes. "Los iraníes necesitan escuchar que si ellos no quieren aceptar la oferta que les hacen los europeos, entonces se impone la demanda ante el Consejo de Seguridad. Creo que nadie les ha dicho las cosas tan claramente como se debía haber hecho. La comunidad internacional debe estar segura de hablar con una fuerte voz a los iraníes sobre el hecho de que es inaceptable disponer del arma nuclear con el pretexto de tener energía atómica para usos civiles". La nueva Secretaria de Estado renovó así la convicción de su gobiemo. Irán debe ser demandada ante el Consejo de Seguridad de Naciones Unidas por violación a las normas internacionales, en materia de no proliferación nuclear. Al mismo tiempo, Rice rechazó la idea de que Washington deba implicarse en las negociaciones directas con Teherán. "Todos saben lo que los iraníes deben hacer. Ellos deben simplemente hacerlo" ("Divergencias americano-europeas sobre Irán", Le Monde, 10 de febrero de 2005).

Una vez más, la hipocresía del gobierno de Bush, la cual invoca la autoridad de Naciones Unidas para guardar la fachada del buen internacionalista, mientras anula - con "el veto de Jonh $\mathrm{Ne}$ groponte" - la decisión de diez miembros del Consejo de Seguridad de detener la construcción del muro de Cisjordania e irrespeta la sentencia de la Corte Internacional de Justicia' sobre el mismo delito internacional. La nueva Secretaria de Estado da muestras de tener una conciencia bastante oscura, al repetir, dos años mấs tarde, las mismas acusaciones de la Resolución 1441, que su amo Bush lanzó contra el gobierno de Irak, a principiós de 2003. Además, da la impresión de que la Secretaria de Estado no está muy informada sobre los grandes temas que los 2500 asistentes de Davos se propusieron reflexionar, en el foro de este año. El unilateralismo del gobierno de Bush está muy reflejado en el discurso de Rice del 8 de febrero, en el Instituto de Estudios Políticos de París.

Ahí, Rice planteó a los europeos que había acuerdo sobre una serie de amenazas que debemos enfrentar hoy día: el terrorismo, la proliferación de armas de destrucción masiva, los conflictos regionales, los estados débiles y el crimen organizado. Sin embargo, no siempre habían enfrentado de la misma manera estos problemas. Reconoció la existencia de desacuerdos. Pero anunció que ya era hora de dejar de lado estos desacuerdos pasados. "Es tiempo de abrir un nuevo capítulo en nuestras relaciones y un nuevo capítulo en nuestra alianza". Estados Unidos está dispuesta a trabajar con Europa sobre las prioridades comunes. Y, en consecuencia, Europa debiera también estar dispuesta a trabajar con ella. "La llave del futuro éxito reside en nuestra capacidad para lograr una colaboración fundada no solo sobre nuestras amenazas comunes, sino sobre proyectos comunes más allá del territorio de la comunidad transatlántica". Ninguna de las cuestiones planteadas por su discurso está relacionada con los seis temas tratados en Davos.

Los cuatro puntos que preocupan a Estados Unidos son el gran Medio Oriente, desde Marruecos hasta Afganistán, donde se propone ayudar a la sociedad civil a acceder a las libertades políticas, económicas y civiles; Irak, cuya población, luego de las elecciones de enero, merece que se le muestre "solidaridad y generosidad", es decir, apoyo político y ayuda para su reconstrucción; el conflicto entre Israel y Palestina, "donde Norteamérica y Europa defienden el principio de dos estados coexis-

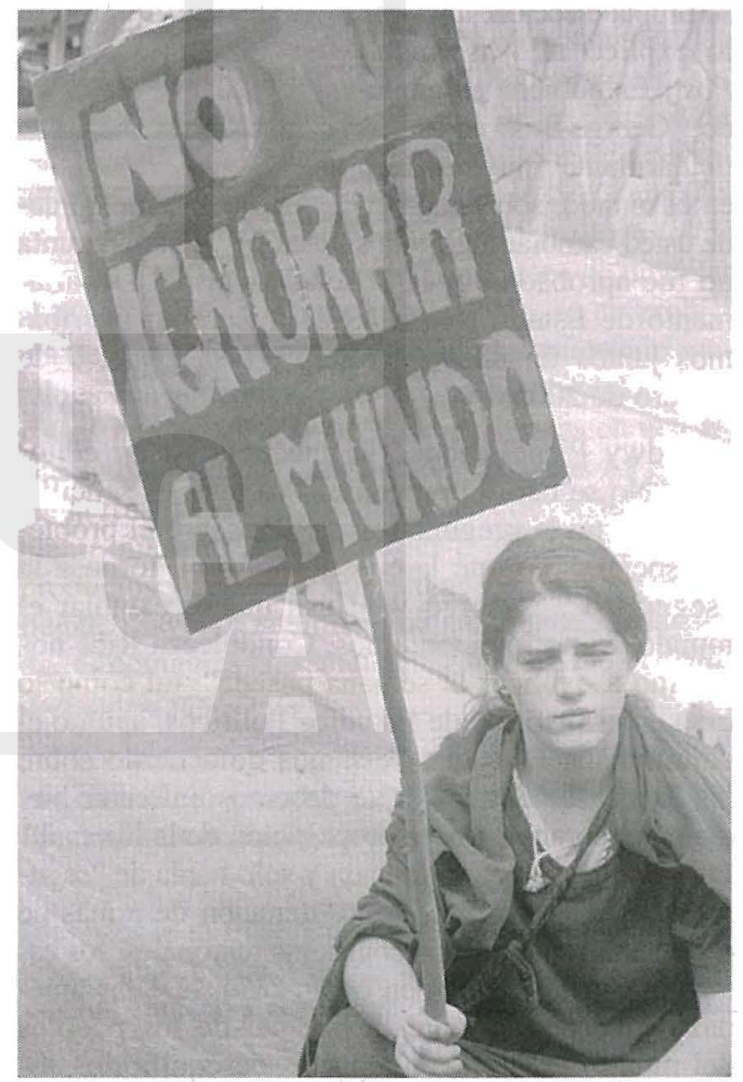


tentes" y donde después de las elecciones y de la propuesta de retiro del territorio de Gaza "se presenta la mejor oportunidad para la paz después de largos años", y El Líbano, el cual debe recuperar su plena soberanía, y de donde Siria debe retirarse y permitir elecciones libres. Llama la atención que, en su discurso, Rice no hiciera mención alguna al tema del uranio nuclear iraní, como problema a resolver entre europeos y estadounidenses.

Una breve anécdota descubre la trastienda de estos discursos. Los invitados a esta conferencia habían recibido el visto bueno de la embajada de Estados Unidos, así como las preguntas que le dirigirían a la Secretaria de Estado. Benjamín Barnier, es decir, hijo del Ministro de Asuntos Exteriores, Michael Bamier, hizo una pregunta sobre el peso y la importancia de los chiítas en Irak; pero esta pregunta no era de su propia elección, tal como lo explicó al Washington Post. El hubiera preguntado, "George Bush no es particularmente muy querido en el mundo, sobre todo en el Medio Oriente. ¿Puede usted cambiar algo esta situación?". Esta pregunta no fue aprobada por la "Escuela", ni del Departamento de Estado ("Mme Rice a Europa: Escribamos juntos un nuevo capítulo", Le Monde, 9 de febrero de 2005).

Edwy Plenel recoge la anécdota en un editorial, "No se hará la pregunta". La tesis es sencilla. En París no le preguntaron a Rice sobre el problema social, sino que la cuestión giró en torno a la "seguridad". "George W. Bush quiere cambiar el mundo. Si no lo entendimos, Condoleeza Rice nos lo vino a explicar la semana pasada", tal como lo hizo en el Instituto de Estudios Políticos, apuntó el editorialista. Dijo que "estamos de acuerdo sobre las amenazas actuales que debemos enfrentar hoy día en el combate por la propagación de la libertad". Pero esa lista es muy limitada y solo habla de "seguridad". "El terrorismo, la proliferación de armas de destrucción masiva, los conflictos regionales, los estados débiles y el crimen organizado. "De las amenazas que pesan sobre la libertad de los pueblos del mundo se excluyen aquí los desequilibrios so- ciales, los desórdenes medioambientales, las desigualdades entre continentes, países y clases, la opulencia, incluso el derroche de unos, la miseria y el hambre de otros, todo lo que emana de la fosa entre ricos y pobres. La libertad de la Condoleeza Rice no se preocupa por la igualdad".

Una revolución bella y muy conservadora. "Se trata de una libertad política que se hermana con la desigualdad social, sin tapujo alguno". Un día antes del discurso de su Secretaria de Estado, en París, Bush había presentado su proyecto de presupuesto para el año 2006, el cual comienza en octubre de 2005 . Aumenta todos los gastos de seguridad militar y espacial, al mismo tiempo que disminuye todos los presupuestos sociales. Vivienda y desarrollo urbano, justicia, medio ambiente, transporte, infraestructura ferroviaria, ayuda a los países pobres, lucha contra la droga en las escuelas, combate contra el analfabetismo, etc. Los doce ministerios y los 150 programas específicos afectados sufren reducciones drásticas, al mismo tiempo que los ingresos fiscales de 2004 han alcanzado los niveles más bajos desde 1959. "iLos ricos pagan cada vez menos y los pobres son cada vez menos atendidos! Socialmente, la revolución de M. Bush y de Mme. Rice es bonita y muy conservadora" ("No se hará la pregunta", Le Monde, 21 de febrero de 2005).

Es un mundo más desigual que nunca. $\mathrm{El}$ informe del Programa de Naciones Unidas sobre el Desarrollo acerca de la democracia en América Latina de 2004, continente que inició el siglo con un elevado número de regímenes democráticos, revela, sin embargo, que la mayoría de los latinoamericanos estarían dispuestos a aguantar un régimen autoritario, si resolviera los problemas sociales. Aunque en estos últimos años, la pobreza aparentemente ha disminuido en porcentajes globales, la fosa social no hace más que aumentar. El 10 por ciento de los latinoamericanos más pobres cuenta con un ingreso cuarenta veces menor que el del 10 por ciento de los más ricos. Hace veinte años, esa diferencia era veinticuatro veces menor. Aunque 
más rico, nuestro mundo globalizado es más desigual que nunca. No hay, pues, que extrañarse del éxito populista de Hugo Chávez o de la popularidad mantenida de la dictadura castrista. Naciones Unidas sugiere un tema molesto cuando señala que la ciudadanía social no es un lujo, sino una condición democrática y que la lucha contra las desigualdades es, realmente, una muestra de la eficacia económica (ibíd.).

Este unilateralismo del gobierno de Bush, asentado en la seguridad militar y alejado de la plena "seguridad humana", nos permite regresar al escenario de los foros mundiales de Davos y Porto Alegre. La razón es la siguiente, el lema o hilo conductor de los debates en el foro económico de Davos 2005 es "ser responsables frente a elecciones difíciles". La guerra de Irak ha sido una elección difícil y equivocada, que ha marcado las divisiones históricas de los años 2003 y 2004 . Los discursos de Bush y Rice son un mal augurio de que las malas elecciones pueden repetirse en el año 2005.

\section{Davos 2005 "con sabor a Porto Alegre"}

Los foros económicos de Davos, donde se reúnen "los maestros del mundo" para otear el horizonte de los negocios, se ven sometidos a los ciclos del buen y del mal humor económico. El foro de 2005 presenta afinidades cercanas con los foros de 1999 y 2004. En 2005 se volvió a afirmar que "la globalización es irresponsable", aunque se usen expresiones distintas a las de Davos 1999, "La globalización debe adquirir un compromiso social, que no tenga como contrapartida la miseria y la exclusión de millones de seres en el planeta". El principal organizador del evento sostuvo, en 1999, "la necesidad de crear mecanismos globales e institucionales para lograr que la globalización se traduzca en fuente de bienestar para millones de personas que han sido condenadas a la miseria y al desempleo". La crisis financiera mundial de 1997 y 1998, seguida de las protestas masivas y de la quiebra de la cumbre de la Organización Mundial del Comercio, en Seattle, mostraron que la globalización no era la respuesta a los graves problemas mundiales.

El foro económico de Davos 2004 estuvo precedido por la tortuosa gestación de la guerra contra Irak, seguida del fiasco planeado de la "organización Mundial del Comercio del Desarrollo", en Cancún, de las resistencias a las reformas internas de Naciones Unidas, en su $58^{\text {a }}$ Asamblea General (2003) y del foro social mundial de Bombay. En este contexto, dos codirectores de Davos 2004 sostuvieron que "La seguridad debe entenderse en un sentido amplio, lo que Naciones Unidas llama 'la seguridad humana'. Los desafíos provocados por el hambre, la pobreza, toda clase de tráficos, la ausencia de un sistema de educación, de salud, o la falta de libertad son realmente gigantescos". Por ejemplo, 800 mil personas murieron el año 2003, en conflictos bélicos; 22 millones murieron por falta de cuidados sanitarios y 800 millones siguen sufriendo de hambre. Más de 42 millones de personas padecen sida y en 2005 serán 100 millones. "Si hoy día 1800 millones viven con menos de un dólar al día ¿es solo problema de ellos? No, es un problema de todos. Sin tomar en cuenta la obligación moral, es conveniente que los países ricos ayuden a los países pobres. ¿Por qué? Porque vivimos en una aldea global cada vez más interdependiente. La pobreza, la frustración de los demás se convierte en problema nuestro: reducción del mercado a nuestros productos y servicios, incremento de la emigración ilegal, mayor contaminación ambiental, enfermedades contagiosas, fanatismo y terrorismo" (Realidad 2004, pp. 25-26).

Por atrición o por contrición, Davos vislumbra la correlación cercana entre crecimiento de la pobreza y gestación del terrorismo.

Davos 2005 tuvo algunos antecedentes favorables, desde la misericordia. El tsunami, con su imponderable número de desaparecidos y entre ellos varios miles de europeos, alcanzó a millones de 
corazones. El 17 de enero 2005, el economista Jeffrey Schas entregó a Kofi Annan un trabajo, preparado durante tres años por 250 expertos, "invertir para el desarrollo: un plan práctico para realizar las metas del Milenio 2000", reducir la pobreza (y otras lacras sociales), a la mitad de ahora al año 2015. Estos objetivos no se están alcanzando, "2005 es la última alternativa para vencer la pobreza". Una señal positiva es que en Davos 2005 no hubo ninguna de primera fila del gobierno de Bush. En las cumbres anteriores, de 2000 a 2003, estas figuras impusieron su agenda. Los discursos de Bush y Rice en Europa son una muestra patente de este absentismo y de esta unilateralidad. Los temas escogidos por los asistentes para reflexionar parecen indicar que "la elite económica mundial estaría apoyando el lema altermundista: otro mundo es posible".

El primer ministro británico Tony Blair se dirigió al nuevo gobierno de Bush, al inaugurar el foro, al cual pidió que "Estados Unidos se asocie a la lucha contra la pobreza". El mismo día que en Irak tenían lugar las elecciones, Blair no habló de la lucha contra el terrorismo, sino de la lucha contra la pobreza y el recalentamiento de la tierra, el cual multiplica la pobreza. ¿Es esto atrición, contrición, es propaganda electoral para recuperar los puntos perdidos con la guerra en Irak? "Lo escrito, escrito está". Blair afirmó que los desafíos del mundo son interdependientes. Estados Unidos sabe que no puede vencer solo el flagelo del terrorismo y, por ello, debe cooperar en la lucha contra los otros desafíos planetarios. "Si Estados Unidos quiere que el resto del mundo participe en los objetivos que él se ha fijado, Estados Unidos debe, por su parte, participar en los otros objetivos. Es absurdo tener que escoger entre una acción que se concentre en el terrorismo y otra sobre la pobreza en el mundo. La lucha antiterrorista, la propagación de la democracia y la paz en el Próximo Oriente son objetivos relacionados entre sí y no pueden disociarse de la ayuda a África, presa de la miseria o de pandemias como el sida y el paludismo o la lucha contra el recalentamiento del planeta, generador de catástrofes". Con dedicación especial al gobiemo de Bush, Blair agregó que "Se puede luchar contra el calentamiento climático sin que ello frene el crecimiento económico, gracias al aporte de la ciencia y de la tecnología".

Es muy importante que Blair, quien presidirá las reuniones del G-8, en 2005, plantee el tema espinoso del comercio internacional, desde la justicia y la equidad. “¿Podemos encontrar una acción que nos integre? Creo que sí... Debemos abrir nuestros mercados, reducir nuestras subvenciones, incluso a productos tan controvertidos como el algodón y el azú. car". Las naciones ricas deben ayudar a África, "para permitir a los países más pobres del continente realizar reformas comerciales capaces de enriquecerles y no empobrecerles". Este año se discutirán, en Hong Kong, los acuerdos comerciales de Doha-Qatar de 2001. Por ello es importante que Blair, jefe de fila del G-8, plantee este tema once meses antes y que lo haga desde una óptica más moral y equitativa ("Tony Blair invita a Estados Unidos a asociarse a la lucha contra la pobreza", Le Monde, 27 de enero de 2005).

A modo de anécdota, el 27 de enero, cientos de participantes asistieron a una sesión titulada, "El G-8 y África, retórica o acción". El estrado fue presidido por Clinton, Blair, Bill Gates, Lula da Silva, Sachs, los presidentes de Nigeria y Sudáfrica, a quienes se sumaron Schröder y Chirac (por video conferencia) y la estrella de rock Bono. Los jefes de Estado desarrollaron el tema central del discurso de Blair, "la guerra a la extrema pobreza". Sachs recordó que, en 1970, los países ricos se comprometieron en dar el 0.7 por ciento del PIB para ayudar al desarrollo, sin ningún resultado. En 1992, de nuevo y de nuevo poco. En 2002, otra vez. Solo cinco países cumplen. Estados Unidos apenas dedica el 0.1 por ciento de su PIB para ayudar al desarrollo.

Como no se ve muy clara la forma de imponer tasas a los movimientos de capital financiero, viajes aéreos o marítimos, Schöder apoyó la propuesta de Blair: crear un instrumento financiero internacional para verter la ayuda prometida, la cual sería dedicada a infraestructura, salud, educación, de manera especial en África, donde el gasto en educación es inferior a un dólar por habitante. "África es un continente rico: los africanos somos pobres". Asimismo, Schröder insistió en la urgencia de dar acceso a los mercados de los países desarrollados a los productos del otrora tercer mundo y se pronunció a favor de quitar las restricciones cuantitativas y reducir las subvenciones agrícolas en Europa, algo que los africanos y otros reclaman, porque les impide competir. En Davos se ha hablado de "ayuda al desarrollo, alivio de la deuda, comercio y globalización equitativa, epidemias y buen gobierno". Este es el año de los desafíos, "un año clave", dijo Gates ("Guerra a la pobreza extrema", El País, 29 de enero de 2005). 
La estrella de rock Bono declaró "Nuestra generación quiere que se acuerden de ella por algo distinto a la guerra contra el terrorismo o el Internet. Queremos ser la generación que quizás pueda poner fin a la pobreza. Dejar un espacio en nuestras estanterías a productos vendidos por los países más pobres", es decir, abrir los mercados a los productos agrícolas. El presidente de Nigeria, O. Obasanjo, dijo que "hay recursos para hacer posible el desarrollo. Pero la seguridad no es una cuestión de armas; para los países de África es alimentación, agua, empleo, salud y educación". El ex presidente Clinton, en discurso aparte, quiso corregir el escepticismo de aquellos que dudan del "nuevo espíritu de Davos". "Sé que mucha gente dice que Davos es un club de ricos esnob, pero gracias en parte a gente presente en esta sala han podido cambiar ciertas cosas. Estamos a años luz de donde estábamos hace diez años. Necesitamos una visión simple y común que genere una serie de acciones. La idea de compartir la prosperidad y la responsabilidad toma fuerza. Es necesario vivir en un mundo con más colaboradores y menos enemigos. Allí vamos a llegar" ("Davos exhorta a "un gran esfuerzo' a favor de África", Le Monde, 28 de enero de 2005).

Más que la pobreza y la desesperanza del tercer mundo, al gobierno de Bush le interesa remendar el distanciamiento con "la vieja Europa" para poder, juntos, controlar los nichos del terrorismo, ahora apellidados tiranía.
Sin duda, las personalidades citadas dicen lo que piensan y piensan con el corazón, pero también es cierto que estas promesas se han repetido tantas veces, en foros anteriores de Davos, en cumbres del G-7, en conferencias de Naciones Unidas - la "cumbre del milenio" o la de Monterrey (2002) - " "para el alivio de la pobreza", que los supervivientes del tercer mundo han perdido la esperanza, la última propiedad que les queda a los pobres. En un breve editorial de El País, "Ptomesas en Davos", se sostiene que "el escepticismo africano está justificado". Y concluye con una frase digna de reflexión cuidadosa, "Davos se ha limitado a registrar que el mundo, desaparecidos otros factores de división, está cada vez más roto entre ricos y pobres. Hay un foso intimidatorio y superlativo: la diferencia de ingresos 'per capita' entre los países menos desarrollados y los de la OCDE, que en 1980 era de 1 a 30 , ha pasado a ser de 1 a 80 . Y esta enorme amenaza - en forma de inseguridad física, económica o social - va a dominar inevitablemen- te la agenda global en 2005" (El País, 1 de febrero de 2005).

La esperanza obliga a afirmar que, después de la cumbre de Davos, los jefes de Estado europeos recibirían a Bush y a su Secretaria de Estado. La visión y los "problemas comunes" de los que Rice habló a los europeos se distancian años luz de los "problemas globales" de Davos. Olvidar estos problemas es "una enorme amenaza", que puede dominar 2005. Los veinticinco jefes de Estado europeos debieran explicarle a Bush cuáles son, en verdad, los "problema globales", de acuerdo al juicio de los 2500 asistentes de Davos. No es fácil imaginar una conversión del impenitente Bush, pero sí es posible esperar un distanciamiento de su unilateralidad.

\section{El foro social en Porto Alegre}

El quinto foro social presenta novedades en su organización y contenido. El que la asistencia haya pasado de unos 20 mil, en 2001, a unos $135 \mathrm{mil}$, en 2005 (otros hablan de 150 mil), significa que el foro es aceptado mundialmente como un lugar de encuentro de los representantes de la sociedad civil y de sus propuestas. Se trata de una sociedad que no participa en Davos, ni se encuentra entre los invitados a las cumbres de los organismos internacionales. Lo importante es que en 2001, Porto Alegre acogió a los miles de "manifestantes pacíficos", presentes en las cumbres mundiales anteriores, deseosos de pasar de la protesta a la propuesta. En el foro social de 2005 , el contenido de las propuestas se ha enriquecido. Aunque la protesta estuvo también presente. El 19 de marzo, en todo el mundo se protestó contra la guerra de Irak.

En este año se levantó el "muro de las propuestas", una lista de 352 propuestas de lo más disímil, provenientes de 150 países. Los participantes de la cumbre anterior de Bombay presentaron la mitad de ellas. En 2006, será necesario distribuir geográficamente las reuniones del foro social por afinidad de temas y problemas, preparados de antemano e integrados luego, a través de las redes de comunicación. Se propuso reforzar la propuesta con 


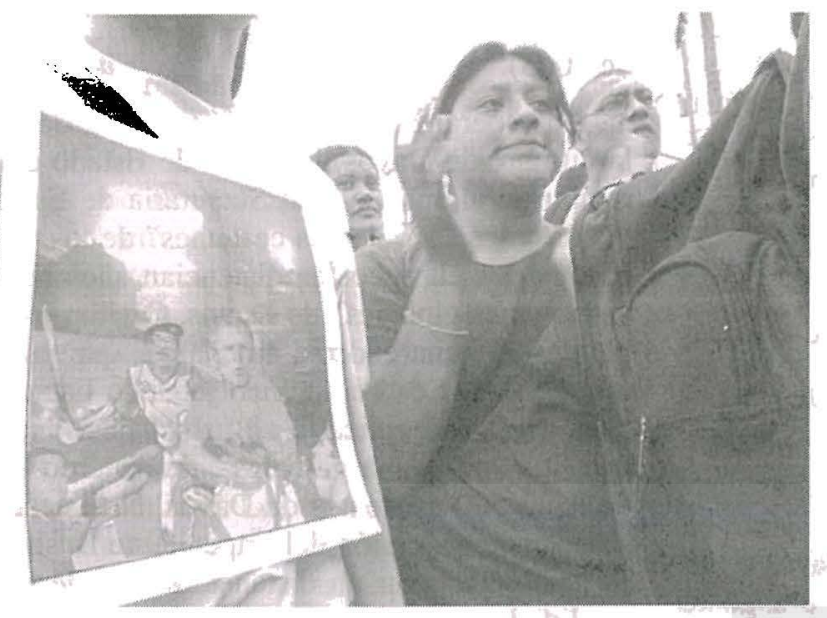

septiembre ha producido un cambio radical. Luego de los actos terroristas, que todos condenamos, como condenamos todos los ataques contra civiles en cual. quier parte del mundo, el gobierno de Estados Unidos y sus aliados han lanzado una operación militar masiva en nombre de la guerra contra el terrorismo. La guerra terrorista contra Afganistán tiende a extender sobre otros frentes. Es el comienzo de una guerra planetaria permanente para consolidar la dominación del gobiemo norteamericano y sus aliados. La guerra revela otra cara del neoliberalismo, brutal e inaceptable" ("Todos a Porto Alegre", Le Monde, 20 de enero de 2002). Esta profecía de 2002

la lucha, con la distribución geográfica del foro en varias naciones (es difícil atender en un solo lugar a 150 mil personas) y establecer fechas para la protesta mundial. Otra novedad de 2005 fue que los representantes del Fondo Monetario Internacional y del Banco Mundial participaron en uno de los debates sobre políticas de ayuda al desarrollo, sobre todo a África ("El foro social mundial de Porto Alegre termina con una serie de propuestas concretas", Le Monde, 31 de enero de 2005).

Una peculiaridad de Porto Alegre 2005 es que comenzó una semana después de la toma de posesión de Bush. Por encima de lo que se podía esperar, la marcha pacífica expres 6 el gran rechazo a sus políticas neoliberales y a su descarada invasión de Irak, "La democracia de las bombas no es el modelo", "Bush el terrorista número uno", "Norteamericanos, salgan de Irak". En Londres, Bruselas, Maguncia y Bratislava, Bush podrá decir a Blair, Chirac, Schröder y Putin: "olvidemos el asunto Irak". Con seguridad, los diplomáticos no hablaran de Irak, en nombre del bien universal. Porto Alegre no es una reunión de diplomáticos, sino de la sociedad civil más golpeada por el modelo neoliberal y donde tienen relevancia especial premios Nobel de la Paz, como Rigoberta Menchú, Adolfo Pérez Esquivel y la iraní Shirin Evadí.

En el foro de Porto Alegre de 2002, Menchú dijo algo que se repitió, "Después de los atentados (del 11 de septiembre), los temas sociales han sido totalmente dejados a un lado, como si el dolor estadounidense hubiera opacado el dolor de todos los otros pueblos que sufren". El documento de Porto Alegre de ese año se inicia con una profecía: "El 11 de es el riesgo de 2005 .

\section{Algunas propuestas económicas}

Una de las 352 sugerencias del "muro de las propuestas" es la inmediata e incondicional cancelación de la deuda externa e ilegítima de los países más pobres del sur, comenzando por los países víctimas del tsunami. La cuestión ha sido discutida también en Davos 2005. Utilizan la expresión "deuda odiosa", una noción de derecho internacional desde 1920.

"No a la guerra de Irak" y a la mentira de las armas de destrucción masiva. No a la amenaza de la guerra contra Irán. Oposición al área de libre comercio de las Américas y no al tratado de libre comercio de Estados Unidos con Centroamérica. Acudir a la próxima cumbre de la Organización Mundial del Comercio, en Hong Kong, en diciembre de 2005, para defender los puntos del acuerdo marco de Ginebra de 2004. Asimismo, hacerse presente en las reuniones del G-8. Una marcha mundial de las mujeres en Burkina Faso, el 17 octubre de 2005, "para reafirmar su compromiso con la lucha contra el neoliberalismo, el patriarcado, la exclusión y la dominación". Apoyo a los movimientos sociales que defiende los derechos de los dalits, los pueblos indígenas, romas, burakumins...

Creación de un impuesto para las transacciones financieras, destinado a financiar el desarrollo. Evitar el "dumping alimentario", las subvenciones masivas, los transgénicos, controlados por cinco internacionales, a favor de la alimentación natural y de la producción agrícola orgánica. Reforma agraria para "los sin tierra". "El agua un bien común". No 
a la privatización del agua. Las energías limpias y un mundo solar. Apoyo al pueblo palestino y "No al muro de Cisjordania". Defensa de los emigrantes, refugiados y desplazados. Apoyo a las campañas y luchas por los derechos de los niños y niñas, contra la explotación laboral y sexual, contra el tráfico de niños y el turismo sexual. Asistir a la Asamblea General de Naciones Unidas, en septiembre, donde se discutirán sus reformas internas y se revisarán sus compromisos para reducir la pobreza. "Apoyamos la economía social como expresión concreta de una alternativa de desarrollo justo, solidario, democrático y equitativo".

Al terminar la reunión se ha dicho que "el foro social mundial se ha institucionalizado; es el espacio más representativo de la sociedad civil. Su inspiración inicial se ha hecho una realidad y no ha disminuido su capacidad de convocatoria". Cándido Grzybowzky, uno de los organizadores, ha dicho que si en Davos se ha discutido "la pobreza" es porque nosotros lanzamos la señal de alarma hace cinco años. Aunque se ha hablado de "Davos 2005 con sabor a Porto Alegre", es la quinta vez que el foro social protesta contra las políticas económicas y comerciales de los países industrializados y las instituciones financieras mundiales. "Pero el blanco principal del presente foro ha sido el presidente Bush, rechazado por su política exterior, sobre todo en Irak" ("La oposición a George Bush congrega a los participantes en el foro social mundial", Le Monde, 27 de enero de 2005; "En cierre del FSM, Movimientos Sociales aprueban plan de acción contra la guerra y el neoliberalismo", Rebelión, 1 de enero de 2005).

\section{Bush quiere acercarse a Europa}

En realidad, Bush busca, en su discurso del 21 de febrero, en Bruselas, que Europa, en bloque, se acerque y se someta a los objetivos geopolíticos de su gobiemo y, por lo tanto, que olvide los enfrenamientos desagradables del pasado, entre otras la mentira de Irak. Alentado por su reelección, los discursos de Bush no buscan tanto un diálogo cercano, sino imponer su fundamentalismo mesiánico. "Hoy Estados Unidos y Europa se hallan frente a un momento importante y trascendental. Juntos, podemos encarrilar la historia sobre el camino de la esperanza: rechazar la pobreza y el desánimo, avanzar hacia el desarrollo y la dignidad por la autodeterminación, alejarse del resentimiento y de la violencia, apegarse a la justicia y a la discusión pacífica en los puntos de divergencia... Las discusiones del pasado desaparecen y surgen claramente los grandes desafíos; inauguremos una nueva era de unidad transatlántica". Esto equivale a proclamarse el dueño del mundo con el poder que le concedería la historia de jugar con el globo de la tierra.

Más que la pobreza y la desesperanza del tercer mundo, al gobiemo de Bush le interesa remendar el distanciamiento con "la vieja Europa" para poder, juntos, controlar los nichos del terrorismo, ahora apellidados tiranía. "Nuestra sólida amistad es esencial para la paz y la seguridad a través del mundo y ningún debate temporal, ningún desacuerdo pasajero de nuestros gobiernos, ningún poder sobre la tierra nos podrá dividir". Para que nadie les pueda dividir, la primera condición es que Europa olvide los desacuerdos, sin utilizar nunca la palabra errores o unilateralidad. En segundo lugar, las tareas que la historia les asigna, las señala Bush. Aunque ha nombrado la pobreza, su interés se centra en su seguridad geopolítica.

Al proponer "La creación de un Estado $\mathrm{Pa}$ lestino y el desarrollo económico de los territorios palestinos" exhíbe su cínica hipocresía, puesto que su embajador en el Consejo de Seguridad de Naciones Unidas adoptó una postura contraria. Lo mismo puede afirmar de su postura ante al muro de Cisjordanía. Los pueblos ocupados son los terroristas y los ocupantes las víctimas. Egipto y Arabia Saudita son amigos muy poco democráticos, pero al igual que en tantos otros casos del pasado, ello no es obstáculo para mantener la amistad de Estados Unidos. China comunista, que encabeza la lista negra de irrespeto de los derechos humanos, es lo mismo. A diferencia de Irán, la "vieja Europa" colabora para que Siria retire sus tropas de El Líbano.

Bush reconoce que algunos países europeos han participado en el combate para la liberación de Irak. Asegura, sin embargo, que sabe reconocer la determinación. "Nosotros la hemos descubierto en el pueblo iraquí. Todas las naciones, en adelante, están interesadas en el logro de un Irak libre y democrático, que combata el terrorismo, que sea como una antorcha de la libertad y constituye un elemento de verdadera estabilidad en la región. En los próximos meses la Asamblea iraquí nuevamente elegida iniciará un trabajo importante, elegir un gobierno, forjar la seguridad, proporcionar los servicios básicos y redactar una Constitución democrática. Ha llegado la hora para todas las democra- 
cias establecidas de proporcionar una ayuda tangible, política, económica y de seguridad a la democracia más joven del mundo". No hay el menor signo de arrepentimiento $\mathrm{y}$, puesto que los equivocados son los no combatientes de 2003, ahora están obligados a reparar su error con la ayuda política, económica y militar. Es el mismo discurso de Powell, en la Asamblea General de Naciones Unidas. Puede que Chirac, Schröder y Putin repitan la misma historia de 2003: cero ayuda económica y militar. Puede que ayuden a la formación de personal administrativo o de seguridad pública.

De cara al "próximo futuro", la sección del discurso dedicada a Irán es importante. "En Irán, el mundo libre comparte un objetivo común. En nombre de la paz, el régimen iraní debe dejar de sostener el terrorismo y no debe crear un armamento nuclear. Para salvaguardar la seguridad de las naciones libres no hay que 'retirar de la mesa ninguna alternativa'. Sin embargo, Irán es distinto de Irak. Estamos ahora en el primer estadio de la diplomacia. Estados Unidos es miembro de la Agencia Internacional de Energía Atómica, que se ocupa de este problema. Trabajamos en estrecha colaboración con Gran Bretaña, Francia y Alemania, que se oponen a las ambiciones nucleares de Irán y que insisten en que Teherán debe respetar los reglamentos internacionales. El éxito de esta tarea común depende en gran medida de Irán". Aquí el peligro de guerra lo puede generar el gobierno de Bush, porque el de Israel puede estar detrás, insinuando las medidas a tomar. Esto es lo que teme el gobierno de Irán. ¿Qué hará la Unión Europea en este caso? No hizo mención explícita a Corea del Norte, que ha confesado disponer de la bomba atómica. Sí se hace una especial mención de "la democracia en Rusia”. Bush explica a Putin qué es y cómo se monta la democracia. El presidente estadounidense olvida que Putín desciende de la $K G B$ rusa y su diálogo puede terminar en distanciamiento ("Bush intenta el acercamiento con la Unión Europea", 21 de febrero de 2005).

\section{Después de Bruselas}

¿Mejorarán las relaciones transatlánticas después del viaje y los discursos de Bush? Por lo que hace a Chirac y Schröder, se puede hablar de "iniciar un diálogo menos tenso". Schröder lo expresó bien, "estamos de acuerdo en no hablar continuamente de lo que nos divide, sino más bien de lo que nos une... Hoy Estados Unidos y Alemania son amigos con derechos iguales, colaboradores y aliados que participan juntos en buscar la solución pacífica en los Balcanes, en Afganistán, en el Próximo Oriente. Alemania, unida y soberana, ha mostrado que está dispuesta a asumir sus responsabilidades internacionales. Tenemos un interés común por un Irak estable y democrático y tenemos la esperanza de llegar a una solución del conflicto palestino-israelí, gracias al firme compromiso de Estados Unidos" ("Bush y Schröder inician una reconciliación", Le Monde, 24 de febrero de 2005).

Distinto ha sido el resultado del encuentro Bush y Putin, en Bratislava. Las alianzas petroleras, los compromisos sobre las ojivas nucleares y la lucha contra el terrorismo, pactada en 2001 y 2002, algo se han enfriado, dado que Bush y Rice, al unísono, critican las disposiciones de Rusia después del atentado del 3 de septiembre 2004, en la escuela de Beslan. Por cierto, algunas de esas medidas poco democráticas no distan mucho de las políticas impuestas por Ascroft, después del 11 septiembre, y por Alberto González, después de Afganistán. Bush y Rice no han hecho más que atizar la nostalgia de la "Gran madre Rusia y del Estado fuerte". Han olvidado que Putin es originario de San Petesburgo ("La guerra sin fin un error", ECA 2004, pp. $1027-$ 1044; "Se multiplican los desacuerdos entre Bush y Putin", Le Monde, 24 de febrero de 2005).

Interesa saber si en Londres o en Washington, Blair le repite a Bush el discurso que éste no escuchó en Davos, y, por lo tanto, le pide que Estados Unidos se asocie a la lucha contra la pobreza. "Si Estados Unidos quiere que el resto del mundo participe en los objetivos que ellos se han fijado, Estados Unidos debe, por su parte, participar en los otros objetivos...". El presidente Bush, y su sombra Rice, ¿estarán abiertos a escuchar este mensaje? ¿Entenderán la pregunta que les hace Ignacio Ramonet?: "¿Terminará también Bush por admitir que los aspectos negativos de la globalización (pobreza agravada de los pobres, injusticias planetarias, rivalidades regionales, desarreglos climáticos, etc.) pueden degenerar en enfrentamientos si no se les opone una concertación multilateral? Pregunta difícil de responder porque el unilateralismo de Bush ve más bien el peligro que las causas del peligro". Por eso, el 58 por ciento de los encuestados por la $B B C$ afirma que la reelección de Bush ha convertido al mundo en un lugar más peligroso.

San Salvador, febrero de 2005. 